\title{
molecules
}

ISSN 1420-3049

http://www.mdpi.org

Full Paper

\section{Synthesis, NMR and Crystallographic Studies of 2-Substituted Dihydroquinazolinones Derived from (S)-Phenylethylamine}

\author{
Jaime Escalante ${ }^{1, *}$, Claudia Ortíz-Nava ${ }^{1}$, Patricia Flores ${ }^{1}$, Jaime M. Priego ${ }^{1}$ and \\ Cirilo García-Martínez ${ }^{2, *}$ \\ ${ }^{1}$ Centro de Investigaciones Químicas, Universidad Autónoma del Estado de Morelos. Av. \\ Universidad No. 1001, Col. Chamilpa, C.P. 62210 Cuernavaca-Mor. México. \\ ${ }^{2}$ Universidad Autónoma Metropolitana, Area de Química. San Pablo No. 180, Col. Reynosa \\ Tamaulipas, México 02200, D.F.
}

* Authors to whom correspondence should be addressed; E-mails: jaime@ciq.uaem.mx or gmc@correo.azc.uam.mx

Received: 5 December 2006; in revised form: 2 February 2007 / Accepted: 5 February 2007 / Published: 12 February 2007

\begin{abstract}
Dihydro-3-[(S)-1-phenethyl]quinazolinone and some new 2-substituted derivatives bearing isopropyl, $o$-nitrophenyl and $p$-nitrophenyl groups were prepared in $40-90 \%$ yield by amidation of isatoic anhydride with (S)-phenylethylamine, followed by condensation with triethyl orthoformate, isopropylaldehyde, o-nitro- and $p$-nitrobenzaldehyde, respectively. The two 2-subtituted dihydroquinazolinones obtained either by using isopropylaldehyde, $o$-nitro- or $p$-nitrobenzaldehyde, were separated and purified before their NMR spectra in $\mathrm{CDCl}_{3}$ solutions were recorded. The detection of the low energy conformation of $\mathrm{O}=\mathrm{C}-\mathrm{N}$-phenethyl segment in solution allowed the correlation of the NMR data with the configuration of newly stereogenic carbon C-2; thus, one diastereomer was labeled SS while the other was RS. Configurations determined by the NMR method were corroborated by X-ray diffraction analysis. X-ray structures of each diastereomeric series showed characteristic conformational types: a propeller-like for the $S S$ and a hairpin for the $R S$ series. Interatomic distances of the hairpin conformation suggest the existence of intramolecular face-to-face interactions between two aromatic rings.
\end{abstract}


Keywords: Chiral dihydroquinazolinones, $\pi$-stacking interactions, NMR method, configurational analysis.

\section{Introduction}

Amidation of chiral primary amines with single enantiomers of methoxytrifluoromethylphenylacetyl chloride and related derivatizing agents is commonly used to determine the configuration of new stereogenic centers by ${ }^{1} \mathrm{H}-\mathrm{NMR}$ spectrocopy [1]. The detection of the low energy conformation 1 of the resulting amides is fundamental to establish the correlation between the chemical shifts $(\delta)$ of the hydrogen nuclei of the amine moiety and the configuration of the chiral derivatizing agent [2]. Although this strategy can be used to study the configuration of cyclic secondary amines, inherent ring conformations and slow rotation about amide bonds (see 2) make it difficult to interpret the NMR spectra [3]. In this context, incorporation of a 1-arylethyl group as the amidic nitrogen substituent, might be the recommended strategy to avoid free rotation about amide bond. Studies carried out with chiral four- and five-membered cyclic amides prepared from a single enantiomer of either arylethylisocyanates [4] or phenylethylamine [5], showed that interaction between the methine hydrogen of the 1-phenethyl group and the carbonyl-oxygen favors the low-energy conformer 3 . Thus, the configuration of new stereogenic centers located in the neighborhood of the 1-phenethyl group, were readily determined from the chemical shifts and the orientation of phenyl ring [4,5].

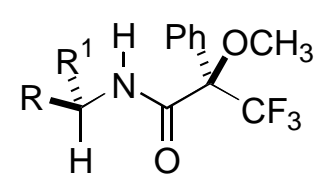

1

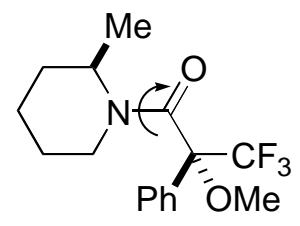

2

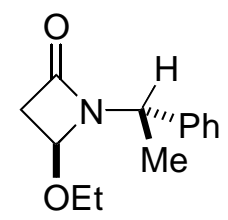

3

Since the 1-phenethyl group can be removed from the heterocycle by hydrogenolysis [6], this strategy is comparable to classical chiral derivatizing methods. In a previous report [5b], we studied the effect of bulky substituents on the orientation of 1-phenethyl group of five-membered ring amides; this time we wish to report the applicability of 1-phenethyl group to six-membered ring amides. Herein we report the synthesis and configurational analysis of some new 2,3-dihydro-3-[(S)-1-phenethyl]quinazolinones 8-11.

\section{Results and Discussion}

\section{Synthesis of dihydroquinazolinones}

The studied products were prepared by the sequence shown in Scheme $1[7,8]$. The reaction of isatoic anhydride (4) with (S)-1-phenylethylamine (5) gave benzamide 6, which was treated with triethyl orthoformate and $p$-toluenesulfonic acid to give 7. Catalytic hydrogenation of $\mathbf{7}$ gave 2,3dihydro-3-[(S)-1-phenethyl]-4-quinazolinone (8). It should be noted that under these conditions 
reductive cleavage of the 1-phenethyl group did not occur, due to the fact that the likelihood of removing this group from an amide is minimal. On the other hand, reactions of 6 with isobutyraldehyde, $o$-nitro- or $p$-nitrobenzaldehyde, gave the corresponding 2-substituted 2,3-dihydro-3[(S)-1-phenethyl]quinazolinones $\mathbf{9 - 1 1}$ in nearly 3:2 diastereomeric ratio and $40-90 \%$ yields (see Experimental section). Based on the assumption that the configuration of (S)-1-phenylethylamine does not change in the two-reaction process [9], we assigned the $S$ configuration to the C9 carbon of 8 (see the numbering system in Scheme 1). Consequently, the configurations of new compounds 9-11 could only be $S S$ and $S R$. Pure diastereomers 9-11 were successfully separated by flash chromatography [10] and analyzed independently by NMR to produce two data sets for each diastereomeric pair. The first eluted diastereomer was labeled as the "less polar" and the next one, as the "more polar". Hereafter, we use the notation $\mathbf{A}$ and $\mathbf{B}$ for the "less polar" and "more polar" diastereomer, respectively.

\section{Scheme 1}<smiles>O=c1[nH]c2ccccc2c(=O)o1</smiles>

4

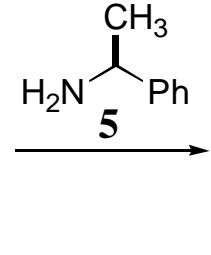<smiles>CC(NC(=O)c1ccccc1N)c1ccccc1</smiles>

6

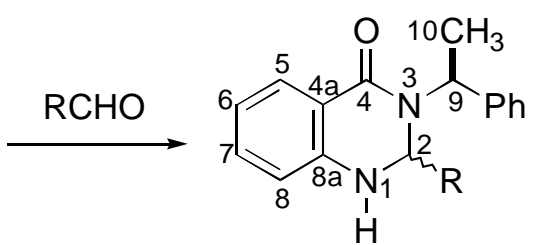

9-11 $\downarrow \begin{aligned} & \mathrm{HC}\left(\mathrm{OC}_{2} \mathrm{H}_{5}\right)_{3} \\ & \text { Toluene / pTsOH }\end{aligned}$<smiles>CC(c1ccccc1)n1cnc2ccccc2c1=O</smiles>

7

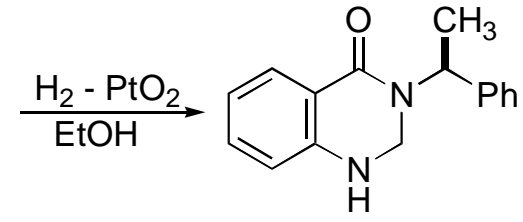

8

9, $\mathrm{R}=i-\mathrm{Pr} ; \mathbf{1 0}, \mathrm{R}=o-\mathrm{O}_{2} \mathrm{NC}_{6} \mathrm{H}_{4} ; \mathbf{1 1}, \mathrm{R}=p-\mathrm{NO}_{2} \mathrm{C}_{6} \mathrm{H}_{4}$

Structure and chemical shift correlations

The studied 2,3-dihydro-3-[(S)-1-phenethyl]quinazolinones have rigid structures with limited degrees of freedom for single bond rotation. Their low energy molecular models, constructed with the MM2 subroutine of CS Chem 3D Pro® program [11], show little pyramidalization of the N1 and N3 nitrogens, which are both almost coplanar with the fused carbocyclic ring. The half chair conformation of the six-membered heterocyclic ring shows C2 out of the plane, with one pseudo-axial and one pseudo-equatorial bond. The substituent attached to C2 is invariably pseudo-axial.

To highlight the usefulness of the NMR method, only $\delta$ values of specific hydrogen atoms attached to $\mathrm{sp}^{3}$ carbons are commented briefly (however, complete data is given in the Experimental section). In the ${ }^{1} \mathrm{H}$-NMR spectrum of $\mathbf{8}$, the diastereotopic hydrogens attached to $\mathrm{C} 2$ (H2) constitute the AB part of an $\mathrm{ABC}$ system. In the spectra of $\mathbf{9 A}$ and $\mathbf{9 B}, \mathrm{H} 2$ constitutes the A part of an ABC system, while in the spectra of 10 and 11, H2 constitutes the A part of an AB spin-spin system. For any diastereomeric pair, $\delta$ values of $\mathrm{H} 2$ (Table 1 ) showed large differences $\left(\Delta \delta=\delta_{\mathrm{H} 2}\right.$ of $\mathbf{A}-\delta_{\mathrm{H} 2}$ of $\left.\mathbf{B}\right)$ and therefore, $\mathrm{H} 2$ can be 
used as the pivotal nucleus to determine the configuration of C2. To fulfill the configurational analysis, one needs to know the dominant conformation of 1-phenethyl group.

Table 1. $\delta_{\mathrm{H} 2}$ Values of dihydroquinazolinones 8-11, obtained from 400 $\mathrm{MHz}$ spectra of $0.5 \mathrm{M}$ solutions in $\mathrm{CDCl}_{3}$ containing $\mathrm{TMS}$ at $25^{\circ} \mathrm{C}$.

\begin{tabular}{cccc}
\hline Compound & $\delta$ diastereomer A & $\delta$ diastereomer $\mathbf{B}$ & $\Delta \delta(\mathrm{ppb})$ \\
\hline $\mathbf{8}$ & $4.174,4.463$ & - & - \\
$\mathbf{9}$ & 4.19 & 4.535 & -340 \\
$\mathbf{1 0}$ & 6.035 & 6.138 & -103 \\
$\mathbf{1 1}$ & 5.481 & 5.674 & -193 \\
\hline
\end{tabular}

Experience and MM2 calculations of the $\mathrm{O}=\mathrm{C}-\mathrm{CHCH}_{3} \mathrm{Ph}$ segment [5a] have shown that in the absence of a large substituent in the proximity of such segment, the most stable conformation of the 1-phenethyl group is that in which the methine hydrogen eclipses the carbonyl carbon [4,5]. Assuming that the steric interaction of the substituent at C2 does not alter this low energy conformer, the position of $\mathrm{H} 2$ and the phenyl ring could be inferred from $\delta_{\mathrm{H} 2}$. Accordingly, diastereomers A must have $\mathrm{H} 2$ in front of the phenyl ring, so that the configuration of C2 in these diastereomers must be $S$, and $R$ that of diastereomers $\mathbf{B}$ (Figure 1). The same conclusion can be drawn by applying this interpretation to the observed $\delta_{\mathrm{CH}}$ of isopropyl group of $\mathbf{9 A}$ and $\mathbf{9 B}$, as well as to the observed $\delta_{\mathrm{Me}}(\mathrm{C} 10)$ of $10 \mathrm{~A}$ and $10 \mathrm{~B}$ or 11A and 11B. In 9B, for instance, the methine hydrogen of the isopropyl lies in the diamagnetic zone of the phenyl ring $\left(\Delta \delta_{\mathrm{CH}}=-750 \mathrm{ppb}\right)$ and in similar way, methyl C10 of 10A and 11A lies in the diamagnetic zone of nitrophenyl ring $\left(\Delta \delta_{\mathrm{Me}}=-509\right.$ and $-464 \mathrm{ppb}$, respectively).

Figure 1. The conformation of 1-phenethyl group, is the key point to assign the absolute configuration of new stereogenic carbon C2 of diastereomers $\mathbf{A}$ and $\mathbf{B}$ by routine ${ }^{1} \mathrm{H}$ - NMR experiments.

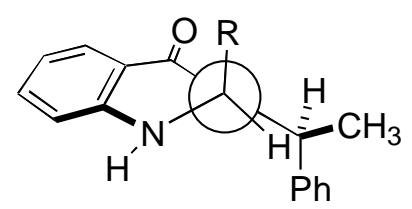

diastereomer A

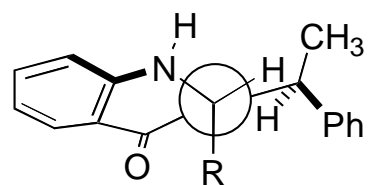

diastereomer $\mathbf{B}$

$X$ ray diffraction

To support the configurational analysis based on NMR spectra, the single crystals of $\mathbf{8}, \mathbf{9 A}, \mathbf{1 0 B}$, 11A and 11B were analyzed by X-ray diffraction [12]. The structures were solved with the SHELXS97® program [13], under the assumption that the stereogenic carbon of the 1-phenethyl moiety retained the configuration of (S)-1-phenylethylamine. The ORTEP drawing of 8 (Figure 2) contains the following features: a peri-type interaction of the carbonyl with $\mathrm{H} 5$ twists the half-chair conformation of the heterocyclic ring, deviating N3 and C4 from the plane of the fused carbocyclic ring. The pyramidal N1 is aligned with the latter ring and the tetrahedral methylene $\mathrm{C} 2$ is out of the 
plane, with one hydrogen pseudo-axial and other pseudo-equatorial. Methine hydrogen H9 is practically coplanar with the carbonyl group $\left(\varphi\right.$ H9-C9-N3-C4 $\left.=-5.0^{\circ}\right)$ and close to the carbonyloxygen; the distance between $\mathrm{H} 9$ and $\mathrm{O} 4$ is $2.33 \AA$. These features prove that the low energy conformation of the 1-phenethyl group is not only a consequence of pure steric interactions of the substituents attached to $\mathrm{C} 2$ and $\mathrm{N} 3$, but also of the $\mathrm{C}-\mathrm{H}^{\cdots} \mathrm{O}$ hydrogen bond. According to the conformation of crystalline $\mathbf{8}, \mathrm{H} 2_{\text {pseudo-equatorial }}$ is within the shielding zone of the phenyl ring and its NMR signal should be expected at high field. The observed chemical shifts of $\mathrm{H} 2_{\text {pseudo-equatorial }}$ and $\mathrm{H} 2_{\text {pseudo-axial }}$ are consistent with this expectation, see Table 1.

Figure 2. ORTEP drawing of compound 8 showing the syn-like conformation of carbonyl C4 and hydrogen attached to C9.

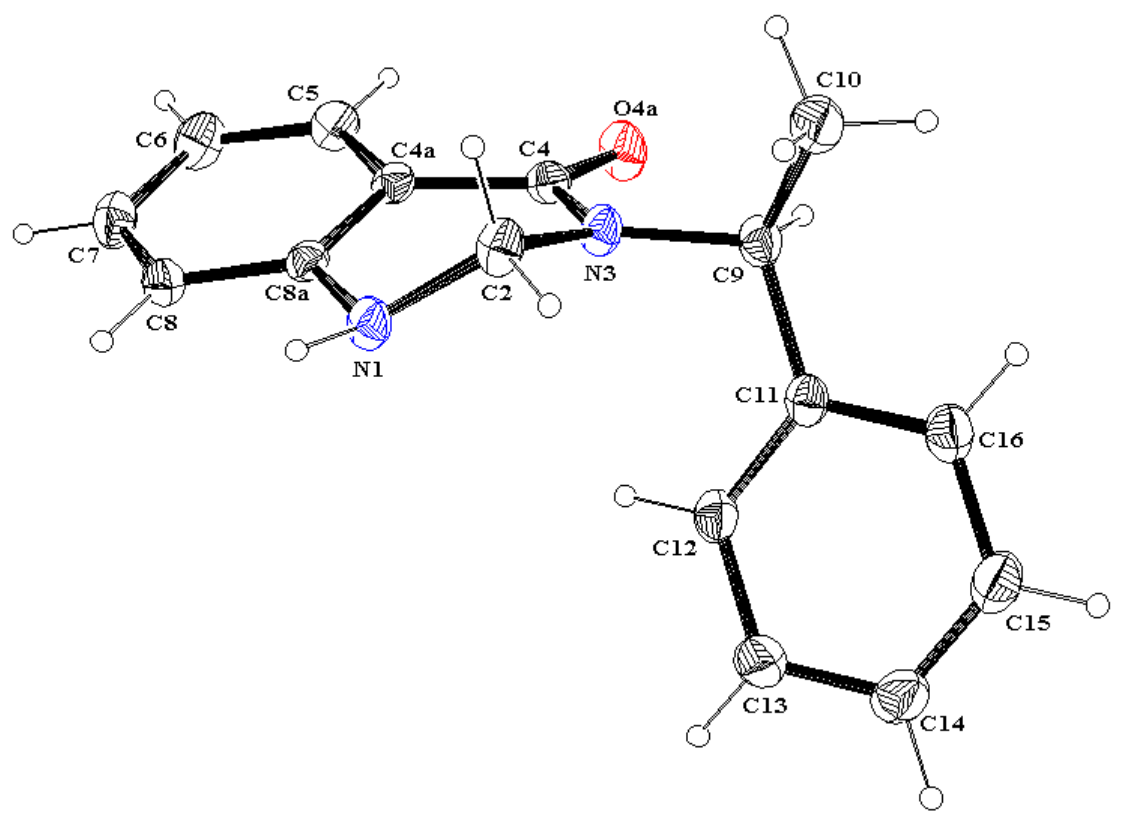

The X-ray structures of $\mathbf{9 A}, \mathbf{1 0 B}, \mathbf{1 1 A}$ and $\mathbf{1 1 B}$ show that isopropyl, $o$-nitro and $p$-nitro groups do not alter the typical conformation of the 1-phenethyl group. We chose $\mathbf{1 1 A}$ and $\mathbf{1 1 B}$ to summarize the molecular features of these 2-substituted 2,3-dihydro-3-[(S)-1-phenethyl]quinazolinones. Thus, X-ray structures 11A and 11B (Figure 3), show essentially the same half-chair conformation of the heterocyclic ring described above for $\mathbf{8}$. Due to the allylic 1,3-effect [14], the p-nitrophenyl group is oriented pseudo-axial. In 11A, the aromatic ring of $p$-nitrophenyl group is oriented towards the N3-C2 bond while in $\mathbf{1 1 B}$, it is oriented towards the heterocyclic ring $\left(\varphi \mathrm{N} 3-\mathrm{C} 2-\mathrm{C}_{i p s o}-\mathrm{C}_{\text {ortho }}=15.5^{\circ}\right.$ and $42.2^{\circ}$, respectively). In $\mathbf{1 1 A}$, the methine hydrogen of the 1-phenethyl group is much more deviated from the carbonyl plane than in $\mathbf{1 1 B}$ ( $\varphi$ H15-C15-N3-C4 $=44.3^{\circ}$ and $-18.1^{\circ}$, respectively) but the distance between $\mathrm{H} 15$ and $\mathrm{O} 4$ is still within the accepted values for hydrogen bonding [15]. The relative orientation of $p$-nitrophenyl and phenyl rings is the marked difference between structures of 11A and 11B. In the crystalline structure, 11A assumes a propeller-like conformation. In contrast, 11B assumes a hairpin conformation in which the phenyl and p-nitrophenyl rings are syn-like and slightly displaced from each other, so their planes are not parallel. Interatomic distances between ipso carbons C9-C17 (3.12 $\AA$ ) and para carbons C12-C20 (4.57 $\AA$ ), however, are small enough to suggest the existence of a stabilizing intramolecular $\pi$-stacking interaction between the two aromatic rings [16]. 
Thus, in addition to the above mentioned $\mathrm{C}-\mathrm{H}^{\cdots} \mathrm{O}$ hydrogen bond, the crystal lattice $\mathbf{1 1 B}$ might be stabilized by intramolecular face-to-face and intermolecular face-to-edge interactions. The analysis of $\mathrm{X}$ ray structures of 10B, 2,3-dihydro-2-(S)-phenyl-3-[(R)-1-phenethyl]- and 2,3-dihydro-2-(S)-omethoxy-phenyl-3-[(R)-1-phenethyl] quinazolinone [7], are consistent with the features mentioned above for 11B.

Figure 3. ORTEP drawings showing the propeller-like and hairpin conformations of compounds $11 \mathrm{~A}$ and $\mathbf{1 1 B}$, respectively. It should be noticed that substituents are labeled with a particular numbering system.

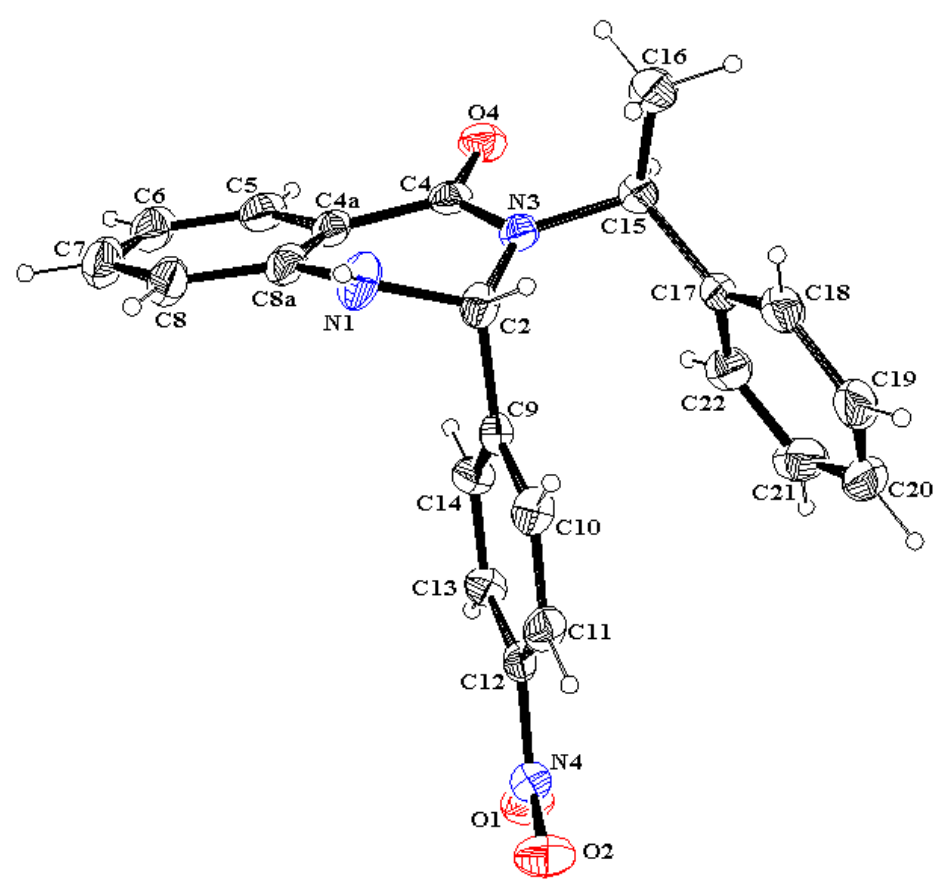

11A

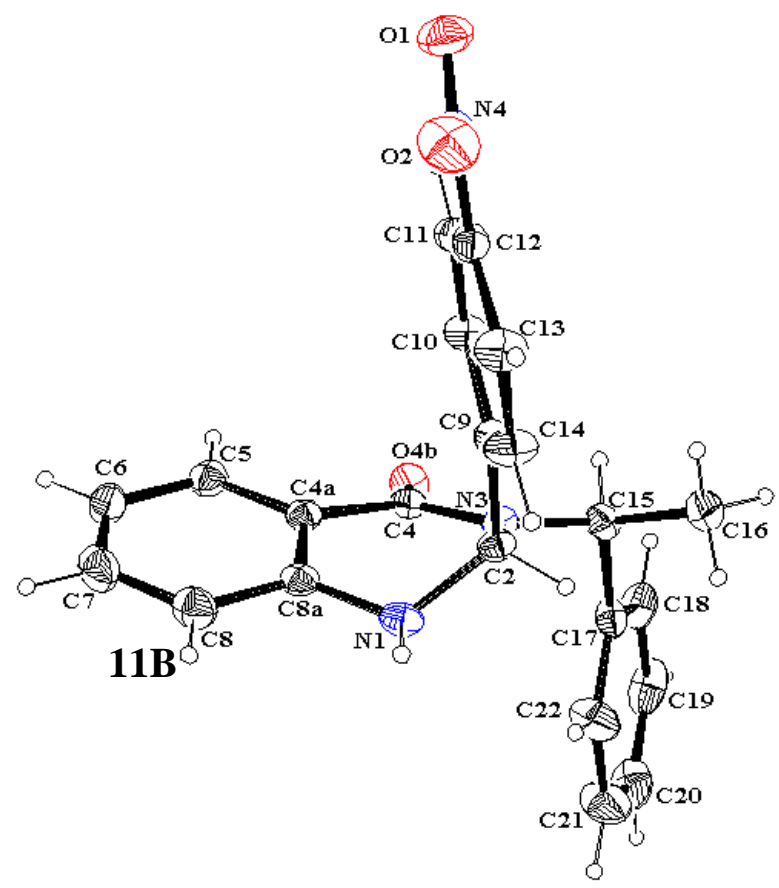

11B

\section{Conclusions}

We have prepared the new compounds 8, 9A, 9B, 10A, 10B, 11A and 11B, and have characterized them by NMR, elemental analysis and X-ray diffraction. Experimental data of studied compounds revealed that a syn-like conformation of the methine hydrogen of the phenethyl group and the carbonyl oxygen is the dominant conformation in $\mathrm{CDCl}_{3}$ solution and in the solid state. Based on this conformation and on the shielding effect caused by phenyl ring on neighboring protons, we assigned the $S S$ configuration to $9 \mathbf{A}, 10 \mathrm{~A}$ and $11 \mathrm{~A}$, and the $R S$ one to $9 \mathbf{B}, 10 \mathbf{B}$ and $11 \mathbf{B}$. The crystalline structure of the SS diastereomeric series derived from monosubstituted benzaldehydes has a propellerlike conformation while the $R S$ series assumes a hairpin conformation. Interatomic distances of the latter arrangement suggest the existence of stabilizing intramolecular $\pi$-stacking interaction between two aromatic rings. 


\section{Experimental}

\section{General}

All melting points were determined with a Büchi apparatus and are uncorrected. Specific rotations was measured in a PerkinElmer 341 polarimeter at $24{ }^{\circ} \mathrm{C}$ and $\lambda=589 \mathrm{~nm}$. Elemental analysis (CHN) was performed on an Elementar Vario EL III elemental analyzer. Proton and ${ }^{13} \mathrm{C}$-NMR spectra were obtained from $0.5 \mathrm{M}$ solutions in $\mathrm{CDCl}_{3}$, containing a small amount of TMS, and recorded on an Inova 400 spectrometer equiped with a $5 \mathrm{~mm}{ }^{1} \mathrm{H}$ probe at $25^{\circ} \mathrm{C}$. All chemical shifts are from TMS signal and ${ }^{1} \mathrm{H}-\mathrm{NMR}$ data are given in the standard format: $\delta$ units, integration, signal multiplicity and coupling constants in Hertz. X-ray diffraction analysis was carried out with an APEX-Bruker diffractometer. The structures were solved by SHELXS97 method and refined by full-matrix least squares. For each crystal, heavy atoms were refined anisotropically while hydrogen atoms were located in the calculated positions.

\section{Synthesis of dihydroquinazolinones}

2,3-Dihydro-3-[(S)-1-phenethyl]-4(1H)-quinazolinone (8) and its 2-substituted derivatives 9-11, were prepared by minor variations of published procedures [17,7]. The physical and spectroscopic data reported herein were obtained with pure diastereomers recrystallized from dichloromethane-hexane.

\section{2,3-Dihydro-3-[(S)-1-phenethyl]-4(1H)-quinazolinone (8)}

Quinazolinone 7 was prepared according to a known procedure [17] and then it was hydrogenated in the following way: a solution of $7(0.5 \mathrm{~g})$ in $\mathrm{EtOH}(10 \mathrm{~mL})$ was mixed with commercial $\mathrm{PtO}_{2}$ catalyst $(0.05 \mathrm{~g})$ and exposed to $30 \mathrm{psi}$ of hydrogen during $2 \mathrm{~h}$ at $25{ }^{\circ} \mathrm{C}$ with shaking in a Parr hydrogenator. The catalyst was filtered through Celite ${ }^{\circledR}$ and the resulting solution was concentrated in a rotavapor. The crude residue was purified via flash chromatography to give compound 8 ( $0.48 \mathrm{~g}, 95 \%$ yield): White solid, mp $119-121{ }^{\circ} \mathrm{C} ;[\alpha]_{\mathrm{D}}{ }^{24}=-91.7 \mathrm{deg} \mathrm{cm}^{2} \mathrm{~g}^{-1}, \mathrm{c}=1.0$ in $\mathrm{CH}_{3} \mathrm{OH} ;{ }^{1} \mathrm{H}-\mathrm{NMR} \delta 1.57$ (3H, d, $J=7.2 \mathrm{~Hz}$ ), 4.17 (1H, dd, $J=2.4,9.2 \mathrm{~Hz}), 4.22(1 \mathrm{H}, \mathrm{s}), 4.46$ (1H, dd, $J=2.0,9.2 \mathrm{~Hz}), 6.10$ (1H, q, $J=7.1 \mathrm{~Hz}), 6.63(1 \mathrm{H}, \mathrm{d}, J=8.0 \mathrm{~Hz}), 6.88(1 \mathrm{H}, \mathrm{ddd}, J=7.9,7.9,0.8 \mathrm{~Hz}),, 7.24-7.41(6 \mathrm{H}, \mathrm{m})$, 7.99 (1H, dd, $J=7.8,1.6 \mathrm{~Hz}$ ); ${ }^{13} \mathrm{C}-\mathrm{NMR} \delta 16.3$, 49.8, 55.0, 115.0, 118.1, 119.9, 127.3, 127.6, 128.7, 129.2, 133.2, 140.2, 147.6, 163.4. Anal. calcd. for $\mathrm{C}_{16} \mathrm{H}_{16} \mathrm{~N}_{2} \mathrm{O}$ : C, 76.10; H, 6.40; N, 11.02. Found: C, 76.16; H, 6.39; N, 11.10. X-Ray crystallographic data of $\mathbf{8}$ is available as supporting information [12].

2,3-Dihydro-(2S)- and 2,3-dihydro-(2R)-isopropyl-3-[(S)-1-phenethyl]-4(1H)-quinazolinone (9A and 9B, respectively)

The crude mixture of 9A and 9B, obtained from 6 ( $1 \mathrm{~g}, 4.0 \mathrm{mmol})$ and isobutyraldehyde $(0.5 \mathrm{~mL}$, $5.0 \mathrm{mmol}$ ) was purified by flash chromatography (silica gel, hexane-dichloromethane-ethyl acetate 70:30:10) to afford $0.44 \mathrm{~g}$ of $\mathbf{9 A}$ and $0.30 \mathrm{~g}$ of $\mathbf{9 B}$. Compound 9A was thus isolated as white solid, $\mathrm{mp}$ $137-139{ }^{\circ} \mathrm{C} ;[\alpha]_{\mathrm{D}}{ }^{24}=-118 \mathrm{deg} \mathrm{cm}^{2} \mathrm{~g}^{-1}, \mathrm{c}=0.7$ in $\mathrm{CHCl}_{3} ;{ }^{1} \mathrm{H}-\mathrm{NMR} \delta 0.78(3 \mathrm{H}, \mathrm{d}, J=6.8 \mathrm{~Hz}), 0.87$ 
(3H, d, $J=6.8 \mathrm{~Hz}), 1.68(3 \mathrm{H}, \mathrm{d}, J=7.4 \mathrm{~Hz}), 2.00(1 \mathrm{H}, \mathrm{m}), 4.19(1 \mathrm{H}, \mathrm{dd}, J=3.6,7.6 \mathrm{~Hz}), 4.28(1 \mathrm{H}, \mathrm{s})$, $6.08(1 \mathrm{H}, \mathrm{q}, J=7.4 \mathrm{~Hz}), 6.52(1 \mathrm{H}, \mathrm{d}, J=8.0 \mathrm{~Hz}), 6.76(1 \mathrm{H}, \mathrm{ddd}, J=7.8,7.8,0.7 \mathrm{~Hz}), 7.18-7.41(6 \mathrm{H}$, m), $7.88(1 \mathrm{H}$, dd, $J$ 7.7, $1.1 \mathrm{~Hz}) ;{ }^{13} \mathrm{C}-\mathrm{NMR} \delta$ 17.2, 18.7, 19.0, 36.6, 52.8, 70.1, 113.8, 118.6, 118.6, 127.8, 128.7, 128.7, 128.8, 133.4, 141.0, 146.5, 163.6; Anal. calcd. for $\mathrm{C}_{19} \mathrm{H}_{22} \mathrm{~N}_{2} \mathrm{O}$ : C, 77.52; H, 7.53; N, 9.52. Found: C, 77.30; H, 7.32; N, 9.00. X-Ray crystallographic data of 9A is available as supporting information [12]. Diastereomer 9B was isolated as a white solid, mp 141-142 ${ }^{\circ} \mathrm{C} ;[\alpha]_{\mathrm{D}}{ }^{24}=$ $24 \mathrm{deg} \mathrm{cm}^{2} \mathrm{~g}^{-1}, \mathrm{c}=1.1$ in $\mathrm{CHCl}_{3} ;{ }^{1} \mathrm{H}-\mathrm{NMR} \delta 0.60$ (3H, d, $\left.J=7.0 \mathrm{~Hz}\right), 0.65$ (3H,d, $\left.J=7.0 \mathrm{~Hz}\right), 1.25$ $(1 \mathrm{H}, \mathrm{m}), 1.75$ (3H, d, $J=7.0 \mathrm{~Hz}), 4.47(1 \mathrm{H}, \mathrm{s}), 4.53(1 \mathrm{H}, \mathrm{dd}, J=7.4,3.0 \mathrm{~Hz}), 5.81(1 \mathrm{H}, \mathrm{q}, J=7.0 \mathrm{~Hz})$, $6.56(1 \mathrm{H}, \mathrm{d}, J=8.0 \mathrm{~Hz}), 6.78(1 \mathrm{H}, \mathrm{ddd}, J=7.5,7.5,1.2 \mathrm{~Hz}), 7.19-7.51(6 \mathrm{H}, \mathrm{m}), 7.87(1 \mathrm{H}, \mathrm{dd}, J=$ 7.6, $1.5 \mathrm{~Hz}) ;{ }^{13} \mathrm{C}-\mathrm{NMR} \delta$ 17.1, 17.7, 18.7, 34.9, 54.2, 71.5, 113.7, 118.8, 118.8, 127.8, 128.0, 128.7, 128.9, 133.4, 133.2, 145.9, 163.3; Anal. Calcd. for $\mathrm{C}_{19} \mathrm{H}_{22} \mathrm{~N}_{2} \mathrm{O}$ : C, 77.52; H, 7.53; N, 9.52. Found: C, 77.00; H, 7.20; N, 9.10 .

2,3-Dihydro-(2S)- and 2,3-dihydro-(2R)-o-nitrophenyl-3-[(S)-1-phenethyl]-4(1H)-quinazolinone (10A and 10B, respectively)

The crude mixture of $\mathbf{1 0 A}$ and 10B, obtained from 6 ( $1 \mathrm{~g}, 4.0 \mathrm{mmol})$ and $o$-nitrobenzaldehyde ( $0.75 \mathrm{~g}, 5 \mathrm{mmol}$ ) was purified by flash chromatography to afford $0.75 \mathrm{~g}$ of $\mathbf{1 0 A}$ and $0.70 \mathrm{~g}$ of $\mathbf{1 0 B}$. Compound 10A was thus isolated as yellowish solid, mp $104{ }^{\circ} \mathrm{C} ;[\alpha]_{\mathrm{D}}{ }^{24}=31 \mathrm{deg} \mathrm{cm}^{2} \mathrm{~g}^{-1}, \mathrm{c}=1$ in $\mathrm{CHCl}_{3}$; ${ }^{1} \mathrm{H}-\mathrm{NMR} \delta 1.18$ (3H, d, $J=7.2 \mathrm{~Hz}$ ), 5.19 (1H, br d, $\left.J \approx 2.4 \mathrm{~Hz}\right), 6.03(1 \mathrm{H}, \mathrm{d}, J=3.2 \mathrm{~Hz}), 6.26$ $(1 \mathrm{H}, \mathrm{q}, J=7.2 \mathrm{~Hz}), 6.45(1 \mathrm{H}, \mathrm{dd}, J=8.0,0.4 \mathrm{~Hz}), 6.86(1 \mathrm{H}$, ddd, $J=7.4,7.4,0.8 \mathrm{~Hz}), 7.20-7.24$ $(1 \mathrm{H}, \mathrm{m}) ; 7.25-7.56$ (9H, m), 7.63 (1H, dd, $J=8.0,1.2 \mathrm{~Hz}) ;{ }^{13} \mathrm{C}-\mathrm{NMR} \delta 17.5,51.5,63.0,115.2,116.3$, 119.6, 125.8, 127.8, 128.1, 128.8, 128.9, 129.0, 129.7, 134.0, 134.0, 136.7, 140.3, 143.9, 146.9, 163.8. Anal. calcd. for $\mathrm{C}_{22} \mathrm{H}_{19} \mathrm{~N}_{3} \mathrm{O}_{3}$ : C, 70.76; H, 5.13; N, 11.25. Found: C, 70.67; H, 5.45; N, 10.5. Diastereomer 10B was isolated as a yellowish solid, mp $173-175{ }^{\circ} \mathrm{C} ;[\alpha]_{\mathrm{D}}^{25}=-359 \mathrm{deg} \mathrm{cm}^{2} \mathrm{~g}^{-1}, \mathrm{c}=1$ in methanol; ${ }^{1} \mathrm{H}-\mathrm{NMR} \delta 1.69(3 \mathrm{H}, \mathrm{d}, J=6.8 \mathrm{~Hz}), 5.24(1 \mathrm{H}, \mathrm{br} \mathrm{d}, J \approx 2.0 \mathrm{~Hz}), 6.14(1 \mathrm{H}, \mathrm{d}, J=2.8 \mathrm{~Hz})$, $6.17(1 \mathrm{H}, \mathrm{q}, J=7.5 \mathrm{~Hz}$ ), 6.45 (1H, ddd, $J=8.1,0.9,0.5 \mathrm{~Hz}), 6.85$ (1H, ddd, $J=7.5,7.5,1.2 \mathrm{~Hz}), 7.16$ (1H, ddd, $J=7.5,7.5,1.2 \mathrm{~Hz}), 7.19-7.63(9 \mathrm{H}, \mathrm{m}), 8.02(1 \mathrm{H}, \mathrm{dd}, J=7.8,0.8 \mathrm{~Hz}) ;{ }^{13} \mathrm{C}-\mathrm{NMR} \delta 17.2$, 52.0, 62.8, 114.9, 116.7, 119.6, 124.7, 128.0, 128.2, 128.4, 128.6, 128.7, 133.3, 133.9, 136.0, 137.4, 144.0, 146.5, 163.7; Anal. calcd. for $\mathrm{C}_{22} \mathrm{H}_{19} \mathrm{~N}_{3} \mathrm{O}_{3}$ : C, 70.76; H, 5.13; N, 11.25. Found: C, 70.80; $\mathrm{H}$, 5.10; N, 11.24. X-Ray crystallographic data of $\mathbf{1 0 B}$ is available as supporting information [12].

2,3-Dihydro-(2S)- and 2,3-dihydro-(2R)-p-nitrophenyl-3-[(S)-1-phenethyl]-4(1H)-quinazolinone (11A and $11 \mathrm{~B}$, respectively)

The crude mixture of 11A and 11B, obtained from 6 ( $1 \mathrm{~g}, 4 \mathrm{mmol})$ and $p$-nitrobenzaldehyde (0.75 g, $5 \mathrm{mmol}$ ) was purified by flash chromatography to afford $0.39 \mathrm{~g}$ of 11A and $0.21 \mathrm{~g}$ of 11B.

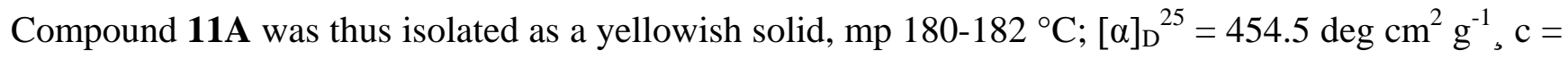
1 in $\mathrm{CHCl}_{3}$; ${ }^{1} \mathrm{H}-\mathrm{NMR} \delta 1.27$ (3H, d, $\left.J=6.8 \mathrm{~Hz}\right), 4.60(1 \mathrm{H}$, br d, $J \approx 2.4 \mathrm{~Hz}), 5.48(1 \mathrm{H}, \mathrm{d}, J=3.2 \mathrm{~Hz})$, $6.37(1 \mathrm{H}, \mathrm{q}, J=7.2 \mathrm{~Hz}) 6.46(1 \mathrm{H}, \mathrm{dd}, J=8.8,0.6 \mathrm{~Hz}) 6.90(1 \mathrm{H}$, ddd, $J=7.3,7.3,0.8 \mathrm{~Hz}), 7.23(1 \mathrm{H}$, ddd, $J=6.9,6.9,1.2 \mathrm{~Hz}), 7.21-8.14(9 \mathrm{H}, \mathrm{m}) 8.04(1 \mathrm{H}, \mathrm{dd}, J=7.6,1.6 \mathrm{~Hz}) ;{ }^{13} \mathrm{C}-\mathrm{NMR} \delta 17.7,51.4$, 66.8, 115.5, 117.3, 120.4, 124.3, 126.7, 127.41, 128.1, 128.9, 134.0, 140.2, 143.5, 148.1, 149.0, 162.8; 
Anal. calcd. for $\mathrm{C}_{22} \mathrm{H}_{19} \mathrm{~N}_{3} \mathrm{O}_{3}$ : C, 70.76; H, 5.13; N, 11.25. Found: C, 70.78; H, 5.18; N, 11.17 . Diastereomer 11B was isolated as a yellowish solid, mp 194-196 ${ }^{\circ} \mathrm{C}$; $[\alpha]_{\mathrm{D}}{ }^{25}=-423 \mathrm{deg} \mathrm{cm}^{2} \mathrm{~g}^{-1}, \mathrm{c}=1$ in methanol; ${ }^{1} \mathrm{H}-\mathrm{NMR} \delta 1.73(3 \mathrm{H}, \mathrm{d}, J=7.2 \mathrm{~Hz}), 4.63(1 \mathrm{H}, \mathrm{d}, J=2.0 \mathrm{~Hz}), 5.67(1 \mathrm{H}, \mathrm{d}, J=2.4 \mathrm{~Hz})$, $6.21(1 \mathrm{H}, \mathrm{q}, J=7.1 \mathrm{~Hz}), 6.47$ (1H, dd, $J=8.4,0.4 \mathrm{~Hz}), 6.91(1 \mathrm{H}, \mathrm{ddd}, J=7.5,7.5,0.9 \mathrm{~Hz}), 6.96-7.02$ (1H, m), $7.17-7.81(9 \mathrm{H}, \mathrm{m}), 8.02(1 \mathrm{H}, \mathrm{dd}, J=7.8,1.2 \mathrm{~Hz}) ;{ }^{13} \mathrm{C}-\mathrm{NMR} \delta 17.1,51.8,67.1,115.3$, 117.3, 120.4, 123.5, 126.3, 128.0, 128.2, 128.3, 128.8, 134.0, 138.4, 143.8, 147.4, 148.0, 162.6; Anal. calcd. for $\mathrm{C}_{22} \mathrm{H}_{19} \mathrm{~N}_{3} \mathrm{O}_{3}$ : C, 70.76; H, 5.13; N, 11.25. Found: C, 70.57; H, 5.17; N, 11.05. X-Ray crystallographic data of $\mathbf{1 1 A}$ and $\mathbf{1 1 B}$ is available as supporting information [12].

\section{Acknowledgments}

We are grateful to Consejo Nacional de Ciencia y Tecnología de México for grants 38187E, 48356Q, 32261E, and scholarships awarded to Flores P., Priego J. M., and Ortiz-Nava, C.

\section{References and Notes}

1. Seco, J. M.; Quiñoá, E.; Riguera, R. The Assignment of Absolute Configuration by NMR. Chem. Rev. 2004, 104, 17-118.

2. Hoye, T. R.; Renner, M. K. Applications of MTPA (Mosher) Amides of Secondary Amines: Assignment of Absolute Configuration in Chiral Cyclic Amines. J. Org. Chem. 1996, 61, 84898495.

3. Rauk, A.; Tavares, D. F.; Khan, M. A.; Borkent, A. J.; Olson, J. F. Conformational analysis of chiral hindered amides. Can. J. Chem. 1983, 61, 2572-2580.

4. García-Martínez, C.; Taguchi, Y.; Oishi, A.; Hayamizu, K. Configurational 1H NMR study of optically active 7-(1-phenylethyl)-2-oxa-7-azabicyclo[3.2.0]heptan-6-one derivatives using Pirkle's alcohols and a chiral shift reagent. Magn. Res. Chem. 1998, 36, 429-435.

5. (a) Bongini, A.; Cardillo, G.; Orena, M.; Porz, G.; Sandri, S. A new synthesis of both the enantiomers of 4-amino-3-hydroxybutanoic acid (gabob) and $\mathrm{mm} 2$ calculations for rotamers of the intermediate oxazolidin-2-one. Tetrahedron 1987, 43, 4377-4383; (b) García-Martínez, C.; Cervantes-Cuevas, H.; Escalante-García, J. Synthesis and NMR Configurational Analysis of 1,3Imidazolidin-4-ones Derived from (-)-(S)-Phenylethylamine. Chirality 2003, 15, S74-S81.

6. (a) Juaristi, E.; Rizo, B.; Natal, V.; Escalante, J.; Regla, I. Alternative method for the resolution of 1-benzoyl-2-tert-butyl-3-methyl-1,3-imidazolidin-4-one. Tetrahedron: Asymmetr. 1991, 2, 821826. (b) Hazelard, D.; Fadel, A.; Girard, C. Stereoselective synthesis of (1R,2R)-1-amino-2hydroxycyclobutanecarboxylic acid-serine derivative-, from racemic or optically active 2benzyloxycyclobutanone Tetrahedron: Asymmetr. 2006, 17, 1457-1464.

7. Escalante, J.; Flores, P.; Priego, J. M. Synthesis of 1,2-dihydroquinazolin-4(1H)-ones Heterocycles 2004, 63, 2019-2032.

8. Connolly, D. J.; Cusack, D.; O’Sullivan, T. P.; Guiry, P. J. Synthesis of quinazolinones and quinazolines. Tetrahedron 2005, 61, 10153-10202.

9. Cardillo, G.; Tomasini, C. In Enantioselective synthesis of $\beta$-aminoacids; Juaristi, E., Ed.; JW Wiley: N.Y. 1997; pp. 211-248. 
10. Still, W. C.; Kahn, M.; Mitra, A. Rapid chromatographic technique for preparative separations with moderate resolution. J. Org. Chem. 1978, 43, 2923-2925.

11. CS-Chem3D Pro 3.5.1/Chem Office 4.0, CambridgeSoft, Cambridge, MA, 1997.

12. Crystallographic data of $\mathbf{8}, \mathbf{9 A}, \mathbf{1 0 B}, \mathbf{1 1 A}$ and $\mathbf{1 1 B}$ are deposited with the Cambridge Crystallographic Data Center (CCDC \# 627346, 264374, 264375, 264376, and 264377, respectively). These data can be obtained free of charge from The Cambridge Crystallographic Data Centre via www.ccdc.cam.ac.uk/data_request/cif.

13. Sheldrick, G. M. SHELX97, Programs for Crystal Structure Analysis, release 97-2; Germany, 1998.

14. Seebach, D.; Lamatsch, B.; Amstutz, R.; Beck, A.; Dobler, M.; Egli, M.; Fitzi, R.; Gutschi, M.; Herradón, B.; Hidber, P.; Irwin, J.; Locher, R.; Maestro, M.; Maetzke, T.; Mouriño, A.; Pfammatter, E.; Plattner, D.; Schickli, C.; Schweizer, W.; Seiler, P.; Stucky,G.; Petter, W.; Escalante, J.; Juaristi, E.; Quintana, D.; Miravitlles, C.; Molins. Structure and Reactivity of Fiveand Six-Ring $N, N-, O-$, and $O, O$-Acetals: A Lesson in Allylic 1,3-Strain (A1,3 Strain). E. Helv. Chim. Acta 1992, 75, 913-934.

15. The interatomic distance, in angstroms, between the methine hydrogen at C9 or C15 and the oxygen at C4 is as follows: 9A, 2.275; 10B, 2.280; 11A, 2.486; 11B, 2.316.

16. Mei, X.; Wolf, C. Highly Congested Nondistorted Diheteroarylnaphthalenes: Model Compounds for the Investigation of Intramolecular $\pi$-Stacking Interactions. J. Org. Chem. 2005, 70, 22992305.

17. Priego, J.; Flores, P.; Ortiz-Nava, C.; Escalante, J. Synthesis of enantiopure cis- and trans-2aminocyclohexane-1-carboxylic acid from octahydroquinazolin-4-ones. Tetrahedron: Asymmetr. 2004, 15, 3545-3549.

Sample Availability: Small samples (a few milligrams) of 8, 9, 10 and $\mathbf{1 1}$ are available from the authors.

(C) 2007 by MDPI (http://www.mdpi.org). Reproduction is permitted for noncommercial purposes. 